\title{
Serum fibrin/fibrinogen degradation products as a prognostic index in acute myocardial infarction
}

\author{
SAMARENDRA-LAL-CHOUDHURY, JOHN ROSSFORD EDGE, AND \\ DEREK STANSFIELD
}

From the Departments of Medicine and Pathology, North Lonsdale Hospital, School Street, Barrow-in-Furness, Cumbria

SYNOPSIS A study of the prognostic value of serum fibrin/fibrinogen degradation products (FDP) in 137 consecutive patients with acute myocardial infarction showed a positive correlation between high FDP levels and poor prognosis. Both the frequency of complications and the mortality were related to increased levels of FDP, the highest of which were found between the fourth and eighth days after infarction.

In recent years the estimation of serum fibrin/ fibrinogen degradation products (FDP) after myocardial infarction has attracted the attention of many physicians and biochemists. Baele et al (1972) and Simmons et al (1973) all report a poor prognosis in patients with high levels following the acute incident. Almér et al (1972) also found significantly larger infarcts, as judged by serum transaminase and lactic dehydrogenase levels, in patients with increased circulating FDP.

\section{Material and Methods}

In the present investigation 137 consecutive patients, admitted to North Lonsdale Hospital between October 1972 and November 1973 with positive clinical enzymatic and electrocardiographic evidence of myocardial infarction, were studied. Only those who fulfilled the criteria of 'very probable' myocardial infarction, as laid down in the World Health Organization technical report series (1959) were examined. All who showed any clinical or radiological evidence of pulmonary embolism, or any signs of deep vein thrombosis, were excluded. To this end each patient was carefully examined daily for clinical evidence of deep vein thrombosis, which included the presence of calf pain, tenderness, oedema, dilatation of superficial veins, and temperature difference in the legs.

A diagnosis of pulmonary embolism was accepted

Received for publication 7 April 1975. on the clinical criteria of chest pain, dyspnoea and/or haemoptysis, with or without direct evidence of right-sided heart failure. Appropriate radiological and electrocardiographic examinations were carried out whenever indicated but were not regarded as essential to the diagnosis. A number of patients were excluded, therefore, on suspicion only of these complications.

\section{Technique}

Five specimens of blood, taken on alternate days, were obtained from each patient. Two millilitres of blood was collected using a dry plastic syringe, with the minimal possible venous occlusion and especial care to ensure a clean venepuncture. The specimen was placed in a glass sample tube containing soya bean trypsin inhibitor ( 3600 NF units per tube) and $20 \mathrm{NIH}$ units of bovine thrombin. The sample was mixed gently, but thoroughly, by inverting the capped tube several times. The blood was allowed to clot for $30 \mathrm{~min}$, and the serum was separated by centrifugation and transferred to a second tube for storage at $-20^{\circ}$ Centigrade until assayed. For labelling purposes the date of clinical onset of infarction was taken as day 0. FDP in serum were assayed by an haemagglutination inhibition technique employing a commercial kit (Wellcome FDP Kit, Wellcome Reagent Ltd) and the results were expressed as $\mu \mathrm{g} \mathrm{FDP} / \mathrm{ml}$ serum.

In the system under consideration fibrinogen has been removed by the clotting mechanism reinforced 
by the addition of thrombin, and the resultant fibrin has been removed by centrifugation. The serum under test therefore contains only soluble FDP. The results of the assay were recorded by one of us (DS) who was ignorant of the clinical features of the patient. Not until the end of the trial were the serum levels released for correlation with the other features (including serum aspartate aminotransferase (SGOT) serum alanine aminotransferase (SGPT), and serum lactate dehydrogenase (LDH) values). Electrocardiograms were taken on admission, and repeated as required, and were recorded on a proforma along with the clinical details.

\section{Results}

On clinical grounds, the 137 patients were divided into two main groups:

Group A consists of $92(67 \%)$ patients who made an uneventful recovery during their stay in the hospital and have since remained well.

Group B consists of the remaining $45(33 \%)$ patients who either died in hospital, had complicated convalescence, or who died shortly after returning home.

All patients have been followed up from a minimum of three to a maximum of 12 months from the acute incident. Of the 45 patients in group B, $31(69 \%)$ died in hospital, and $10(22 \%)$ died after theirreturn home. The remaining four $(9 \%)$ each had a very stormy convalescence due to the development of major complications of myocardial infarction, but all four are still alive after at least three months follow-up.

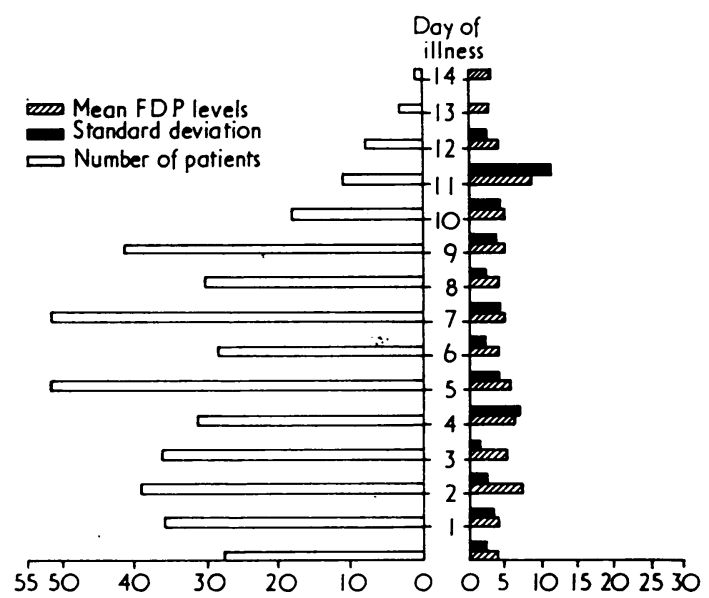

Fig 1 Mean FDP levels $(\mu \mathrm{g} / \mathrm{ml})$ related to day of illness in 92 patients (group A) with satisfactory recovery

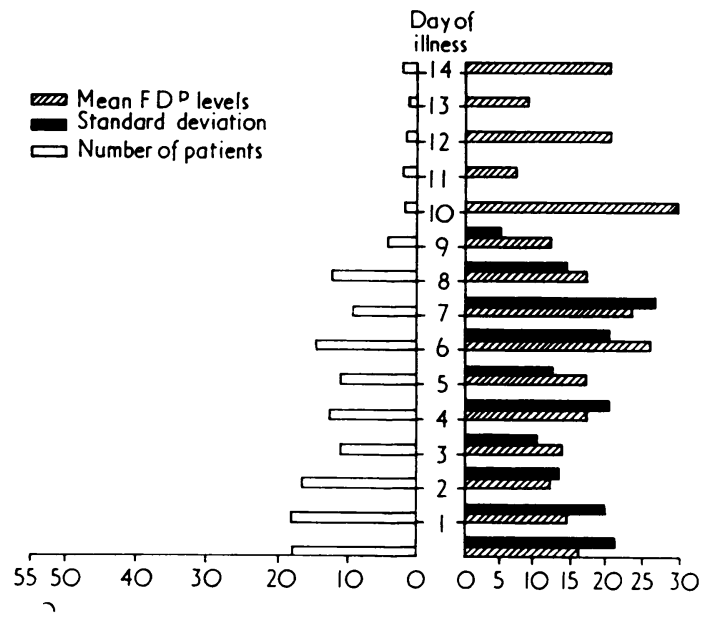

Fig 2 Mean FDP $(\mu \mathrm{g} / \mathrm{ml})$ levels related to day of illness in 45 patients (group B) who died or who had serious complications

The FDP levels in both groups are shown as histograms in figures 1 and 2.

GROUP A

Eighty-two patients in group $\mathrm{A}$ had serum FDP values less than $10 \mu \mathrm{g} / \mathrm{ml}$ in all specimens. The remaining 10 had a serum FDP concentration of more than $10 \mu \mathrm{g} / \mathrm{ml}$ on one or more occasions. Figure 1 shows the level of FDP in the patients in group A.

GROUP B

Thirty-six of $45(80 \%)$ patients in group B had a serum FDP level greater than $10 \mu \mathrm{g} / \mathrm{ml}$ on one or more occasions, and the variation in FDP correlation in the patients in the group is shown in figure 2 . Of the remaining nine $(20 \%)$ patients who had a serum FDP concentration below $10 \mu \mathrm{g} / \mathrm{ml}$, eight died within 24 hours of the infarction (ie, day 0 ), almost certainly before there was time for any rise in serum levels to take place.

Figure 2 shows that the highest levels of serum FDP in the majority of patients of group B were obtained between the fourth and eighth days of illness. Figure 3 shows the FDP values of the patients in groups A and B relating to the day of illness. It can be seen that there is a clear separation between mean FDP values in patients of groups A and B. Determination of FDP values in individual patients (fig 4) supports this view. In all, 91 of the 137 patients (82 in group $A$ and nine in group B) produced serum FDP concentrations below $10 \mu \mathrm{g} / \mathrm{ml}$. All the 82 patients of group A maintained satisfactory clinical progress and of the nine in group B, 


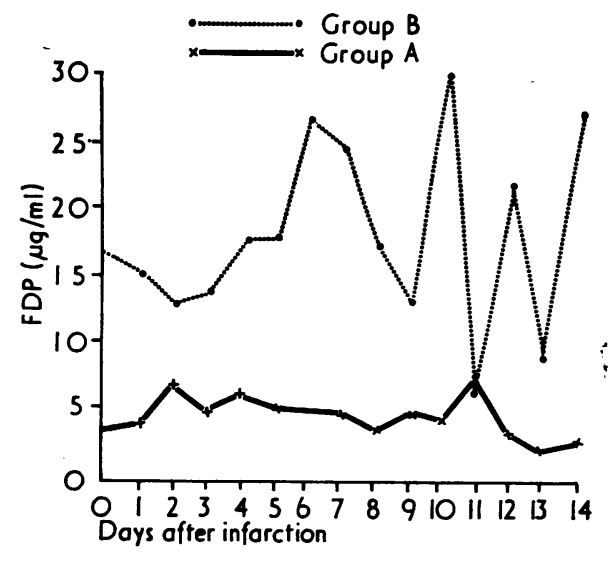

Fig 3 Mean FDP values of patients in groups $A$ and $B$ related to day of illness

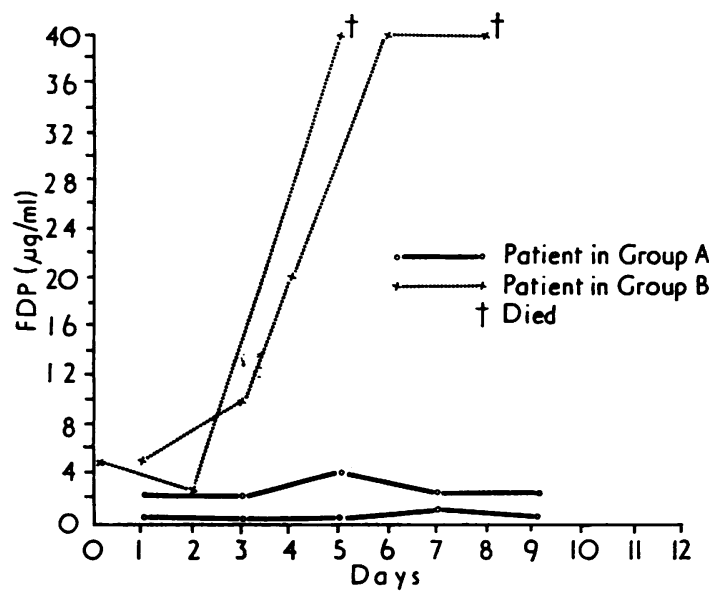

Fig 4 FDP levels in individual patients

eight died on day 0 , so that there was no opportunity for a possible rise in the FDP levels to develop. The remaining patient in group B who recorded low levels died 48 hours after infarction.

\section{Discussion}

\section{THROMBOTIC COMPLICATIONS}

High levels of serum FDP have been found in other conditions including pulmonary infarction (Cash et al, 1969) and dissecting aortic aneurysm (Almér et al, 1972). It has been observed by Simmons et al (1973a) that deep vein thrombosis is more common in patients who develop dysrhythmias and heart failure following infarction. However, deep venous thrombosis and pulmonary embolism are difficult to diagnose with certainty in all cases, and their true incidence in our study remains unknown: isotope scanning, because of its uncertain value, was not used. We are satisfied that few if any patients with these complications went unrecognized in the light of careful clinical and radiological scrutiny. Moreover, the rise in FDP associated with pulmonary embolism is usually transient, returning to normal or near normal levels within 24 hours.

\section{MECHANISM OF FDP PRODUCTION}

During the proteolysis of fibrinogen and fibrin by the fibrinolytic enzyme plasmin, several fragments are released which are unclottable and incapable of further digestion. Fibrinogen degradation products can be derived not only from plasmin digestion of fibrin deposited intravascularly, but also from its digestion by less specific proteolytic enzymes acting at extravascular sites. Degradation products in serum samples may also result from the in vitro digestion of fibrinogen or fibrin by plasmin, trypsin, and other proteolytic enzymes, even perhaps by hydrolytic enzymes derived from neutrophilic leucocytes.

\section{METHOD FOR RECOGNITION OF FDP}

Two of these degradation products are stable against further plasmin action and have been shown to contain antigenic determinants identical with parent fibrinogen. Most of the techniques to quantitate the level of FDP in serum are immunological and are based on the antigenic similarity between FDP and the parent fibrinogen molecule. The methods include precipitation, immunoelectrophoresis, red cell haemagglutination inhibition, and the clumping of certain strains of staphylococci.

NORMAL VALUES: SOME CONDITIONS LEADING TO ABNORMALITIES

The mean normal level in resting adults is $4 \cdot 9 \pm 2 \cdot 8$ $\mu \mathrm{g} / \mathrm{ml}$ with no significant sex difference; serum levels are raised in most patients with disseminated intravascular coagulation, with acute occlusive vascular disease, and also in some patients with carcinoma, acute or chronic renal disease, shock due to sepsis, and the acute stage of certain collagen diseases. Though there is no evidence at present to suggest that the serum FDP estimations are of value in the diagnosis of chronic occlusive vascular disease, it has been reported by various workers (Baele et al, 1972; Almér et al, 1972; Simmons et al, 1973b) that the elevated levels recorded during the first one or two weeks following myocardial infarction are related to the frequency of subsequent complications. 
In 138 cases, Baele et al (1973) similarly found that the patients with a serum FDP level of more than $10 \mu \mathrm{g} / \mathrm{ml}$ generally have a bad prognosis, the mortality and frequency of complications being strikingly high. Baele et al (1972) and Almér et al (1972) found a sinister prognosis in 92 patients with raised serum FDP concentration within 24 and 48 hours respectively after infarction. Our findings agree with this in that patients who had a high concentration (more than $10 \mu \mathrm{g} / \mathrm{ml}$ ) within 48 hours after infarction experienced a high mortality (80\%).

Simmons et al (1973b) describe a poor prognosis in 55 patients, with high levels of serum FDP from five to eight days after infarction. Similarly, in our cases the highest levels in the patients of group B were found between the fourth and eighth days after infarction.

\section{Conclusion}

Although the exact mechanism leading to high levels of serum FDP after acute myocardial infarction is not clearly established, our preliminary results confirm previous suggestions that patients with an increased level following myocardial infarction usually have a bad prognosis. Because high levels are found between the fourth and eighth days after infarction, it would seem reasonable to carry out one or two estimations of serum levels during that period. This would help in the selection of high risk patients early in their illness with a view to arranging a longer period of observation in hospital than is usual for those with a good prognosis.

Our thanks are due to Dr A. P. B. Waind, MD, FRCP, consultant physician, under whose care some of the patients were admitted, and to Mr R. N. Nuttall, FIMLT, for technical assistance.

\section{References}

Almér, L. O., Hedner, U., and Nilsson, I. M. (1972). Serum fibrin/fibrinogen degradation products in acute myocardial infarction. Lancet, 1, 960.

Baele, G., Mussche, M., and Vermeire, P. (1972). Serum fibrin/fibrinogen degradation products in acute myocardial infarction. Lancet, 1, 689-690.

Baele, G., Mussche, M., Vermeire, P., and Pannier, R. (1973). Détermination des produits de dégradation du fibrinogène et de la fibrine (P.D.F.) à la phase aiguë de l'infarctus. Arch. Mal. Coeur, 66, 427-429.

Cash, J. D., Woodfield, D. G., Das, P. C., and Allan, A. G. E. (1969). Diagnosis of suspended or occult pulmonary embolus. Brit. med. J., 2, 576.

Simmons, A. V., Sheppard, M. A., and Cox, A. F. (1973a). Deep venous thrombosis after myocardial infarction; predisposing factors. Brit. Heart J., 35, 623-625.

Simmons, A. V., Sheppard, M. A., Sibbald, R., Tate, G., and Roberts, B. E. (1973b). Prognostic value of serum fibrinogen-related antigen levels after myocardial infarco tion. Brit. Heart J., 35, 997-1001.

World Health .Organization (1959). Hypertension art coronary heart disease: classification and criteria fō epidemiological studies. First report of the expert com? mittee on Cardiovascular Diseases and Hypertension. Annex 'The Electrocardiogram in Coronary.Heart Disease'. Techn. Rep. Ser., No. 168, 25-28. Geneva, WHO. 